\title{
RACIAL DIFFERENCES IN NEIGHBORHOOD EVALUATION STANDARDS
}

\author{
CRAIG ST. JOHN \\ University of Oklahoma
}

\begin{abstract}
It is implicit in the literature on neighborhood satisfaction that individuals or groups of people have different standards for evaluating the quality of their neighborhoodsdifferent standards being the result of differences in past experiences or adaptations to present circumstances. However, to date, there has been no research that has tested for individual or group differences in evaluation standards. In this research the hypothesis that blacks and whites have different standards for evaluating the environmental quality of their neighborhoods was tested. I argue that this difference is a result of blacks having much more restricted access to the housing market than whites. The data support this hypothesis.
\end{abstract}

\section{MEASURING QUALITY OF LIFE}

Two basic approaches have been applied to the study of neighborhood or community quality of life. The first of these is the objective social indicators approach (Land, 1971). This approach typically is based on the collection of social, demographic, and ecological data for geographic units of analysis. From these data, judgments are made about various aspects of the quality of life in the areas under observation (Marans and Rodgers, 1975).

More recently, the subjective indicators approach (Andrews and Withey, 1976; Campbell et al., 1976; Campbell, 1981) has been applied to the study of neighborhood or community quality of life (see Marans and Rodgers, 1975; Miller et al., 1980). This approach is based on the assumption that there is an imperfect match between the objective characteristics of neighborhoods or communities and residents' perceptions of neighborhood or community quality (Rodgers, 1982). This lack 
of congruity is thought to exist because personal perceptions of neighborhood or community quality result from "filtering" objective characteristics through standards of comparison that are based on what people think they deserve, expect, or may reasonably aspire to (Campbell, 1981: 22). Standards of comparison for assessing the quality of neighborhood or community environments are thought to be the products of past experiences, adaptation processes, aspiration levels, and individual personality characteristics (Rodgers, 1982). Thus objective characteristics of neighborhoods and communities are indirectly (and not perfectly) linked to perceptions of quality (Marans and Rodgers, 1975).

The argument that there is an indirect link between objective characteristics of neighborhoods or communities and perception of quality is consistent with Rodgers's (1982) study in which he found only a weak relationship between density in urban neighborhoods, an objective characteristic, and overcrowding, a subjective perception of it. This argument also is consistent with research showing that residents in a variety of neighborhoods and communities with diverse objective characteristics report being at least moderately satisfied with them (Wilson, 1962; Gulick et al., 1962; Lansing and Marans, 1969; Marans and Rodgers, 1975; Guest and Lee, 1983a). Accordingly, researchers applying the subjective indicators approach have focused their attention on residents' self-reported satisfaction with their neighborhoods and communities (Marans and Rodgers, 1975; Campbell et al., 1976; Campbell, 1981; Miller et al., 1980; Ladewig and McCann, 1980; Rodgers, 1982).

Most research utilizing the subjective social indicators approach has focused on the determinants of neighborhood or community satisfaction. Race, social class, home ownership, and age have been found to be related to satisfaction with the neighborhood or community (Marans and Rodgers, 1975). However, these relationships have tended to be very modest, providing additional support for there being an imperfect link between objective conditions and subjective assessments. Very little attention has been given to understanding the nature and/or origins of differences in the standards of comparison that are used to produce subjective evaluations of neighborhood or community quality. This is somewhat surprising since it is the presumed existence of differences in such evaluation standards that motivates the subjective indicators approach.

Recently, research has begun to address this issue. Based on evidence that people of differing social class positions report being at least 
moderately satisfied with neighborhoods or communities of varying "objective" quality, St. John and Clark (1984a) reasoned that there might be social class differences in the standards on which neighborhoods or communities are evaluated. It might be that members of different social classes base evaluations of their neighborhoods or communities on assessments of different characteristics. Such differences could result from differences in cultural orientations or from adaptations to realistic expectations for residential environments, making it possible for people in all types of neighborhoods or communities to evaluate them in terms of characteristics that would yield favorable evaluations.

This hypothesis is supported by some literature that suggests that what people find rewarding in their residential environments varies according to socioeconomic status and accompanying lifestyle orientations (Fried and Gleicher, 1961; Gans, 1962; Suttles, 1968, 1972; Muller, 1981; Berry and Kasarda, 1977). St. John and Clark (1984a) produced support for this hypothesis by demonstrating a strong inverse relationship between class and the rated importance of such neighborhood characteristics as the proximity of friends, relatives, churches, local stores, and places of employment. If lower-class people place more emphasis on these characteristics in evaluating their neighborhoods than those with higher status, then it is reasonable that the former can be equally or nearly as satisfied with their neighborhoods as the latter even though certain "objective" features of their neighborhoods would suggest otherwise.

St. John and Clark (1984a) also found that blacks rated these "local orientation" characteristics as more important for their neighborhoods than did whites. This racial difference could be due to differences in cultural orientation placing greater emphasis on the family and the local community, or it could be due to adapting expectations for desired neighborhood characteristics to restrictions that limit the variety and quality of black objective residential choice. In either case, if blacks place a heavy emphasis on these characteristics in the evaluation of their neighborhoods, it is reasonable to find that racial differences in neighborhood satisfaction are not great even though apparent objective differences in neighborhood quality might exist.

In addition to there being differences in the characteristics on which evaluations of neighborhood or community quality are based, there might also be systematic group differences in the standards of evaluation. If differences in evaluation standards exist, then it would be possible for people from two or more neighborhoods of varying 
"objective" quality to be similarly satisfied with them or people from two "objectively" identical neighborhoods to express different levels of satisfaction. This notion also is consistent with the literature showing people from a variety of neighborhoods being similarly satisfied with them.

There appears to be no research to date that explicitly tests the hypothesis that differences in evaluation standards exist even though such differences are central to the subjective quality-of-life approach. ${ }^{1}$ However, some recent research is consistent with the hypothesis. For example, St. John and Clark (1984a) found no evidence of race or class differences in the importance of neighborhoods being well-cared for and safe. With equal importance given these characteristics by everyone, it is reasonable to expect that those people living in neighborhoods that are of lower environmental quality and/ or less safe will be less satisfied with their neighborhoods, at least in terms of these characteristics.

However, St. John and Clark (1984b) found no evidence of race or social class differences in self-reported satisfaction with the environmental and safety characteristics of neighborhoods. This finding is inconsistent with an abundant literature demonstrating that crime rates and the likelihood of victimization in neighborhoods are inversely related to social class composition and that blacks have a much higher likelihood of victimization in their neighborhoods than whites (Hindelang et al., 1978; Skogan and Maxfield, 1981; Karmen, 1984). ${ }^{2}$ Furthermore, this finding is inconsistent with commonsense evidence that social class is positively related to housing quality and overall neighborhood upkeep and that black neighborhoods have greater problems of cleanliness and congestion than white neighborhoods (Newman and Duncan, 1979; Stipak and Hensler, 1983).

That St. John and Clark (1984b) found a lack of congruity between some objective characteristics of neighborhoods and subjective evaluations of them suggest that there are race and/or social class differences in the standards used to evaluate them. In this research, we provide a test of the hypothesis that there are systematic group differences in the standards used to evaluate certain characteristics of neighborhoods. This was achieved by comparing evaluations by blacks and whites of the environmental characteristics of their neighborhoods while controlling for objective measures of these characteristics. However, before turning to this analysis, a comment is in order justifying the assertion that blacks and whites have different evaluation standards. 
We argue that black/white differences in evaluation standards are the products of past experiences, adaptation processes, and aspiration levels. Blacks have had experiences in the housing market that are different from those of whites, have adapted to the realities of their experiences, and have developed aspiration levels for neighborhood environmental quality that are consistent with the level of quality they may reasonably expect. Residential segregation, which limits the quantity and quality of housing opportunities for blacks in comparison to whites, is the underlying factor responsible for the hypothesized racial difference in environmental evaluation standards.

A large body of literature documents high levels of racial residential segregation in U.S. cities (Taeuber and Taeuber, 1965; Farley, 1977). An important feature of this segregation is that blacks of all levels of social class have fewer opportunities in the housing market than comparable whites. As a result, blacks tend to be channeled into predominantly black neighborhoods where the housing stock is older and more dense and where there are relatively large concentrations of lower-socioeconomic-status blacks (Villemez, 1980). Denowitz's (1980) study of racial invasion and succession in New York City describes this inequity. He found for the decade of the 1960s that black invasion of white residential neighborhoods tended to occur adjacent to established black areas and to be led by the most upwardly mobile members of the black community. During this invasion middle- and upper-class blacks live with whites of similar socioeconomic status. Over time, middle- and upper-class blacks are followed by lower-class blacks as more of the original white residents relocate to newer housing, frequently in the suburbs (Frey, 1979; Marshall, 1979). This pattern of residential change ensures that among blacks, in comparison to whites, there will be less socioeconomic segregation and that middle- and upper-class blacks will have their housing options restricted to neighborhoods that often are of declining status.

Faced with this situation it is possible that black expectations for neighborhood environmental quality come to reflect the realities of their limited opportunities. Blacks, knowing what kinds of neighborhoods they may realistically expect to live in, might develop standards for evaluating them that are less stringent than those of whites. If this is the case, then we might expect both blacks and whites to rate their neighborhoods similarly even if blacks live in neighborhoods with less desirable housing stocks and other environmental conditions. 


\section{RESEARCH DESIGN, DATA, AND METHODS}

The research design required to test this hypothesis is simple. Data that measure the objective environmental characteristics of neighborhoods blacks and whites live in need to be collected and compared to data measuring black and white subjective evaluations of these characteristics. If, when controlling for objective environmental characteristics of neighborhoods (and socioeconomic status), it is found that blacks rate the environmental characteristics of their neighborhoods (subjective evaluations) more favorably than whites, then there will be evidence in support of the hypothesis that blacks and whites have different evaluation standards.

Data to test this hypothesis were collected in conjunction with the 1984 Oklahoma City (OKC) Survey. The OKC Survey is conducted annually by the Department of Sociology at the University of Oklahoma. The 1984 OKC Survey was based on a simple random sample of 350 Oklahoma City residents drawn from the Polk Directory of all adult residents in Oklahoma City. ${ }^{3}$ In addition, data were collected from a supplemental sample of black respondents drawn at random from areas in Oklahoma City known to have large proportions of blacks in their populations. ${ }^{4}$ In this manner, 87 black respondents were added to the sample. Combining the regular and supplemental samples and removing all cases who were not black or white and for whom data were missing on relevant variables yielded a working sample of 412 cases. $^{5}$

To measure subjective evaluations of neighborhood environmental characteristics, respondents were asked to indicate on a four-point scale ranging from strongly agree to strongly disagree if a series of seven statements about the environmental conditions of neighborhoods accurately described their neighborhoods. This procedure allows respondents to define their neighborhoods on their own terms rather than attempting to impose on respondents any definitions of neighborhoods that might be inaccurate. The seven statements describing the environmental conditions of neighborhoods are presented in Table 1 .

These statements describe a combination of possible social and physical environmental characteristics of neighborhoods, indicators of whether or not a neighborhood would be considered a good place to live (Guest and Lee, 1983b). Of the seven statements, five pertain directly to how neighborhood residents take care of the neighborhood. These are the ones measuring pride in neighborhood appearance, litter, respect for 
TABLE 1

\section{Statements Describing the Environmental Conditions of Neighborhoods}

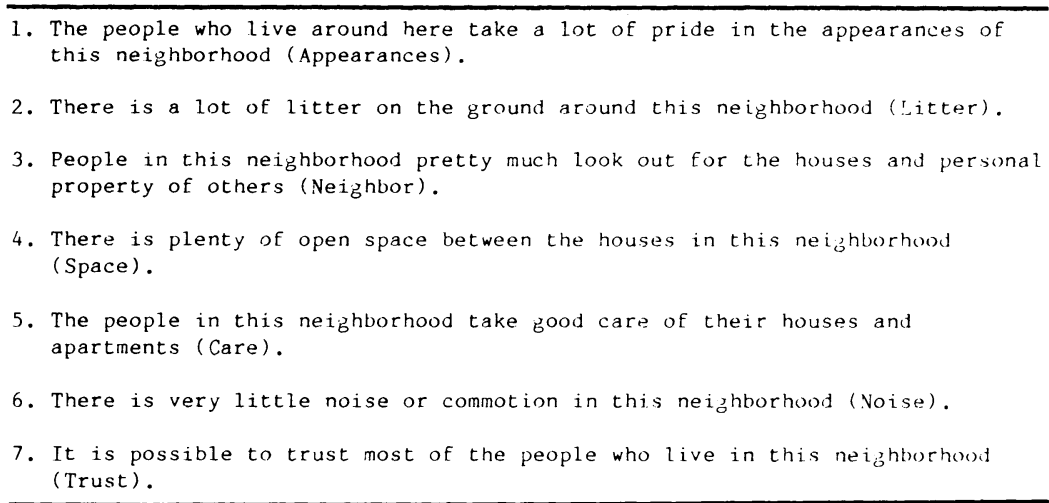

the personal property of others, taking care of one's own personal property, and noise. More important, although each of these statements is related to physical environmental quality, they are indicators of the extent to which residents of a neighborhood are perceived to behave in a manner that is not threatening to the social status and integrity of the neighborhood (Berry and Kasarda, 1977).

These statements appear to be distinct from others that are indicators of perceived neighborhood safety and security. An additional statement measuring ability to trust neighbors is an obvious indicator of social environmental quality. One statement measuring the amount of open space between houses pertains directly to physical environmental quality. This statement fits in well with the others as a social symbol of the type of people who live in a neighborhood. Thus when referring to "neighborhood environment" or "environmental quality," the reference is to a generalized combination of social and physical attributes that contribute to neighborhoods being perceived as good places to live. It is appropriate to focus on this particular aspect of neighborhood quality since research has shown perceptions of the social and physical environmental quality of neighborhoods to be the most important determinants of overall neighborhood satisfaction (St. John and Clark, 1984b; Hertirg and Guest, 1985).

A factor analysis of these seven environmental quality items was performed along with five items measuring perceptions of neighborhood personal and property safety. This analysis demonstrated that all 
seven environmental items are indicators of a single underlying environmental dimension, and that this dimension clearly is distinct from a dimension measuring personal and property safety. ${ }^{6}$

Respondents also were asked to indicate on a four-point scale, ranging from very satisfied to very dissatisfied, their levels of satisfaction with their neighborhoods on each of these characteristics. Respondents' levels of satisfaction regarding the environmental characteristics of their neighborhoods are thought to be a function of subjective evaluations of these characteristics. Therefore, the relationship between subjective evaluations of characteristics and satisfaction with them was expected to be very strong.

Objective neighborhood characteristics were measured in two ways. Records were kept of the addresses of all respondents. With these addresses it was possible to link 1980 census tract data for the tracts respondents lived in to the interview data on subjective evaluations. Census tracts are assumed to be reasonable proxies for neighborhoods. From the census tract data information was obtained on percentage of the adult tract population with 16 or more years of education, the median value of owner-occupied housing, median household income, and the percentage of all housing units that were owner occupied. The percentage of tract population that was black was excluded as a indicator of objective quality for two reasons: First, because this variable is highly correlated with the most important independent variable, race, its inclusion would produce a high level of collinearity and make the interpretation of results for race problematic. Second, the percentage of tract population that was black was not considered to be an objective measure of quality except insofar as it is correlated with the other indicators.

These data are good objective indicators of environmental quality as defined for this research. Percentage of adult tract population with a college education and median household income reflect lifestyle orientations that include both manners of behavior and expectations for the behavior of others. Education and income are assumed to be positively correlated with a concern for upward social mobility and for protecting the integrity of the residential environment as a reflection of achieved status. Accordingly, the class composition of a neighborhood should be a good indicator of environmental quality. The link between median value of owner-occupied housing, percentage of all housing units that are owner occupied, and objective environmental quality is even more apparent. People who own their homes have a bigger stake in 
maintaining the residential environment than renters, and people who own expensive homes have a larger investment than others. To the extent that investment in a neighborhood through home ownership is accompanied by a desire to protect that investment and behavior to fulfill that desire, the tract home ownership variables should be good indicators of environmental quality.

In addition, a member of the research team visited each address and made an assessment of objective neighborhood quality using the Texas Pictorial Technique (TPT; Texas Department of Community Affairs, 1973). The TPT produces a scale measuring housing quality and neighborhood upkeep. ${ }^{7}$ Since most housing units are fairly similar in quality to others in the immediate neighborhood, this scale provides an accurate objective measure of that aspect of neighborhood environmental quality reflected by physical appearance. This scale is highly correlated with the census tract data measures of quality. Since a preliminary factor analysis indicated that the census tract measures and the TPT scale all have high loadings on a single factor, they were treated as multiple indicators of a single underlying dimension. ${ }^{8}$

In addition to respondent's race (coded 1 if black and 0 if white), one other variable was included in the analysis: socioeconomic status (SES). SES was measured in terms of family income, occupation of the head of the household (Duncan scale), and education of the head of the household.

Joreskog and Sorbom's (1981) full-information, maximum-likelihood LISREL program was used to analyze the data. LISREL allows one to treat satisfaction with neighborhood environmental quality, subjective evaluation of neighborhood environmental quality, objective neighborhood environmental quality, and SES as unobserved variables for which there are multiple indicators. ${ }^{9}$

\section{ANALYSIS}

Table 2 shows racial differences in the objective measures of neighborhood environmental quality and in subjective evaluations of environmental quality. In the top panel of Table 2, white neighborhoods are shown, on average, to score higher on all five measures of objective quality than black neighborhoods. These racial differences appear as racial differences in subjective evaluations in the bottom panel of Table 2. For all seven items measuring subjective evaluations, whites are more 
TABLE 2

Racial Differences in Objective and Subjective Neighborhood Environmental Characteristics ${ }^{\mathrm{a}}$

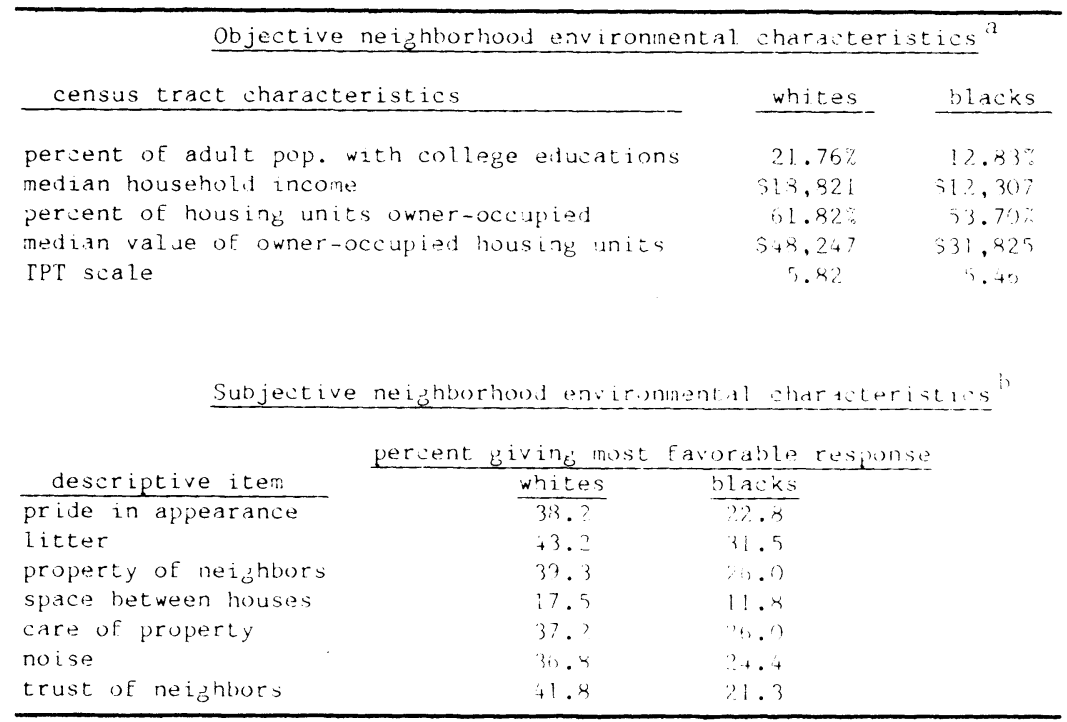

a. All racial differences are significant at the $p<.05$ level.

b. The "litter" item is worded so that "strongly disagree" is the most favorable response. All other items are worded so "strongly agree"' is the most favorable response.

likely than blacks to give the most favorable response as a description of their neighborhoods. These findings demonstrate some congruity between the objective conditions of black and white neighborhoods and subjective evaluations of them. However, it remains to be seen if, at similar levels of objective quality, blacks and whites report similar or different levels of subjective evaluation.

Figure 1 depicts a LISREL model that begins to answer this question. In this model the loadings of the observable indicators on the unobserved endogenous variables all are significant at the $p<.05$ level. ${ }^{10}$ The $\chi^{2} / \mathrm{df}$ ratio for the model shown is less than two, with the freeing of additional parameters not contributing significantly to an improvement in the fit of this model to the data. All of the structural equation parameters shown in this model are significant at the $p \leq .05$ level.

The direct and indirect effects of race on subjective neighborhood quality are the focus for the interpretation of the model. First, controlling for socioeconomic status, blacks live in neighborhoods that 

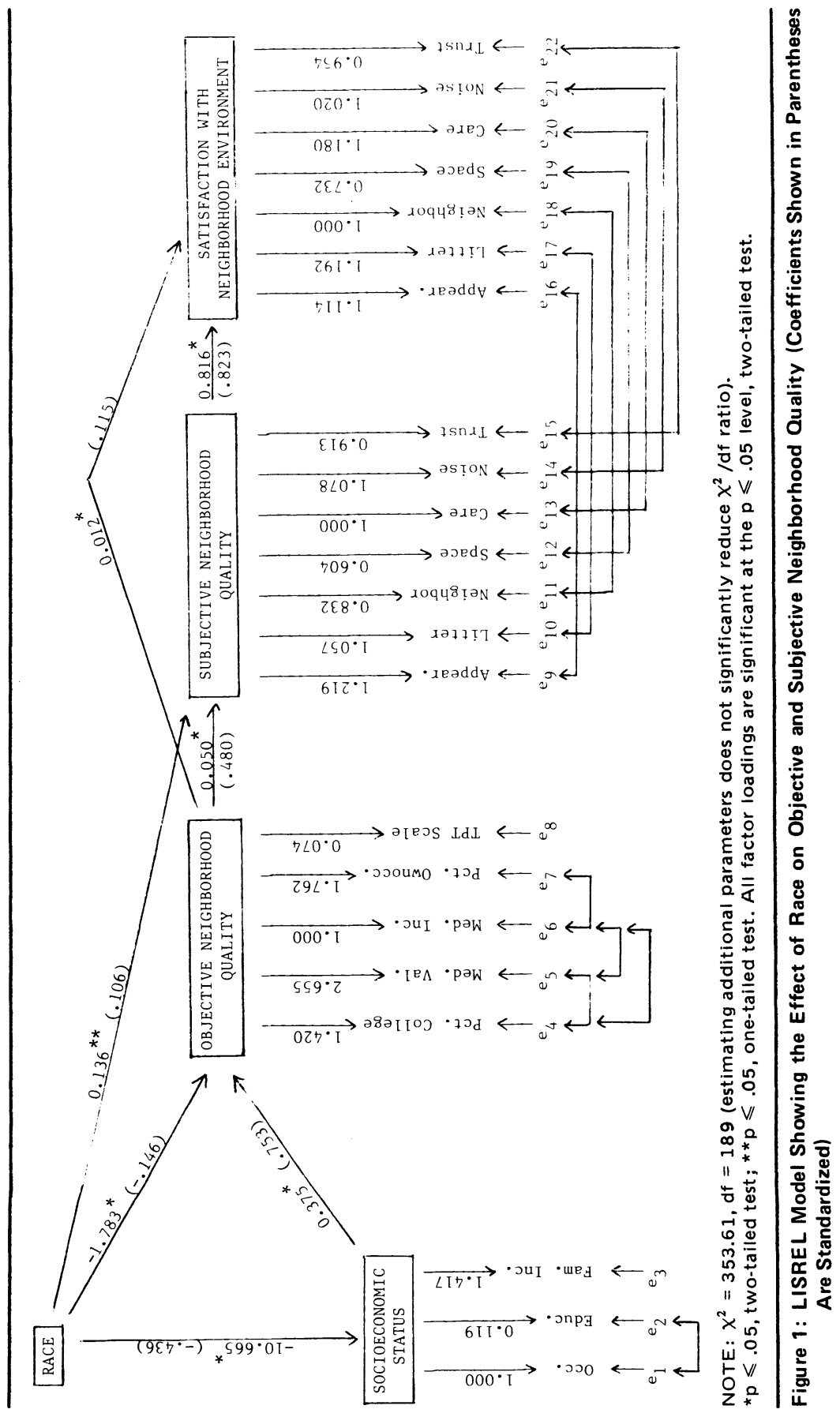
are of lower objective quality than whites, as indicated by the negative coefficient for the path leading from race to objective qualtiy. In addition, because blacks tend to have lower levels of socioeconomic status than whites, and SES is positively related to objective quality, race has a negative indirect effect on objective quality. Furthermore, since objective quality is positively related to subjective quality, race has a negative indirect effect on subjective quality operating through objective quality. Multiplying the relevant standardized coefficients together $[(-0.436 \times 0.753 \times 0.480)+(-0.146 \times 0.480)]$ yields a negative indirect effect of -0.228 .

This negative effect is counteracted to some extent by the positive direct effect race has on subjective quality controlling for socioeconomic status and objective quality. This positive and significant coefficient indicates that if blacks and whites lived in neighborhoods of similar objective quality, blacks would rate the neighborhood more favorably than would whites. In other words, this coefficient is evidence that the black standard for evaluating the environmental quality of neighborhoods is different from that of whites, supporting the hypothesis.

Finally, because of the strong positive effect of subjective quality on satisfaction with the neighborhood environment, the direct and indirect effects of race on subjective quality are transferred into satisfaction with the neighborhood environment. The result is that blacks are only slightly less satisfied with their neighborhood environments than whites, even though there is a fairly large racial difference in the objective environmental conditions of neighborhoods.

Figure 1 demonstrates that blacks and whites have different standards for evaluating the environmental quality of their neighborhoods. Figures 2 and 3 provide additional insight into how this difference in evaluation standards operates by applying a LISREL model separately for whites and blacks. That blacks have evaluation standards different from those of whites should appear as a racial difference in the coefficient leading from objective quality to subjective quality; the coefficient should be higher for blacks than whites. This would account for the positive and significant effect of race on subjective quality in Figure 1.

Figures 2 and 3 indicate that the effect of objective neighborhood quality on subjective neighborhood quality is greater for blacks than for whites. ${ }^{11}$ The unstandardized coefficient for the path leading from objective quality to subjective quality is 0.043 for blacks and 0.015 for whites. LISREL provides a statistical test for the difference between 


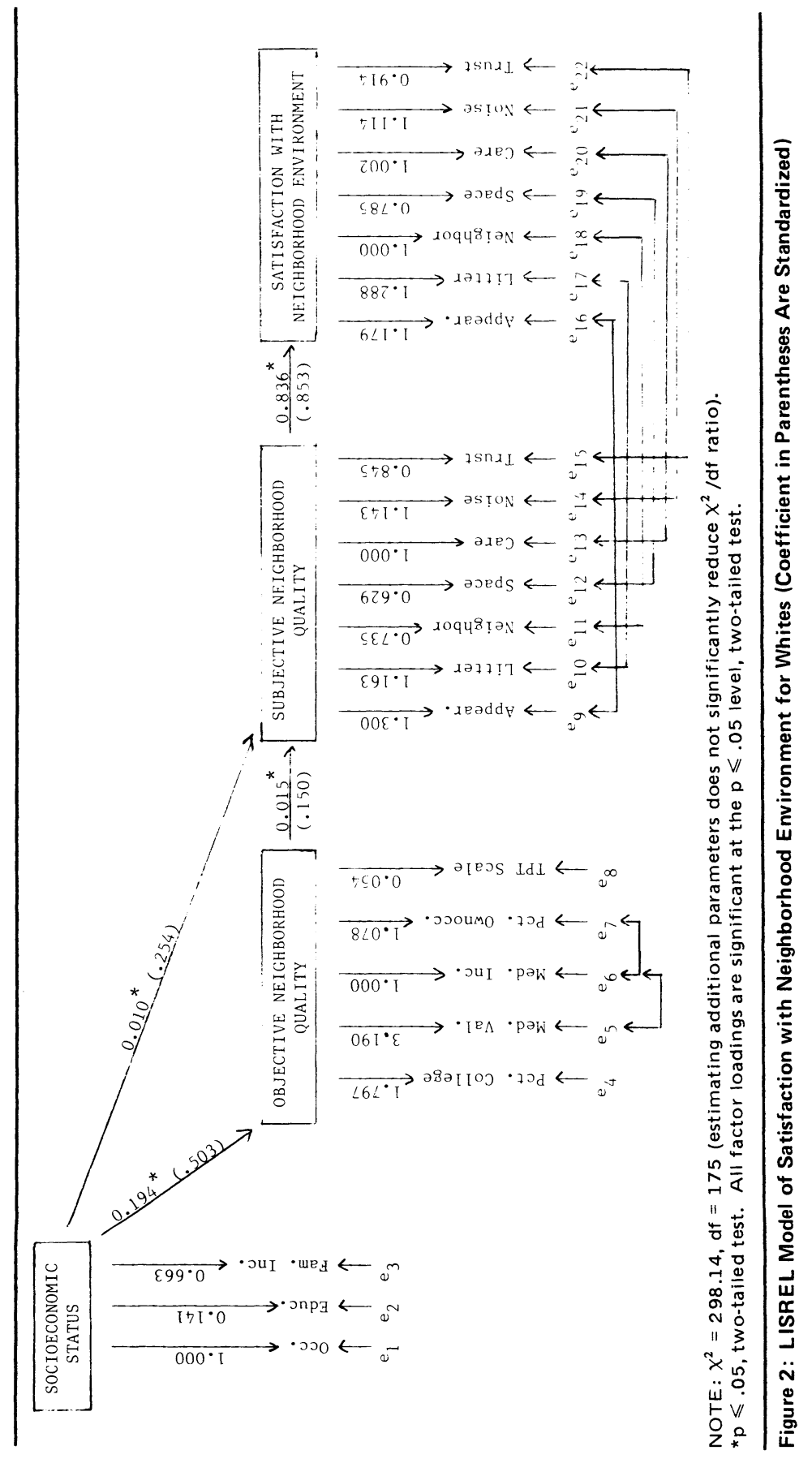




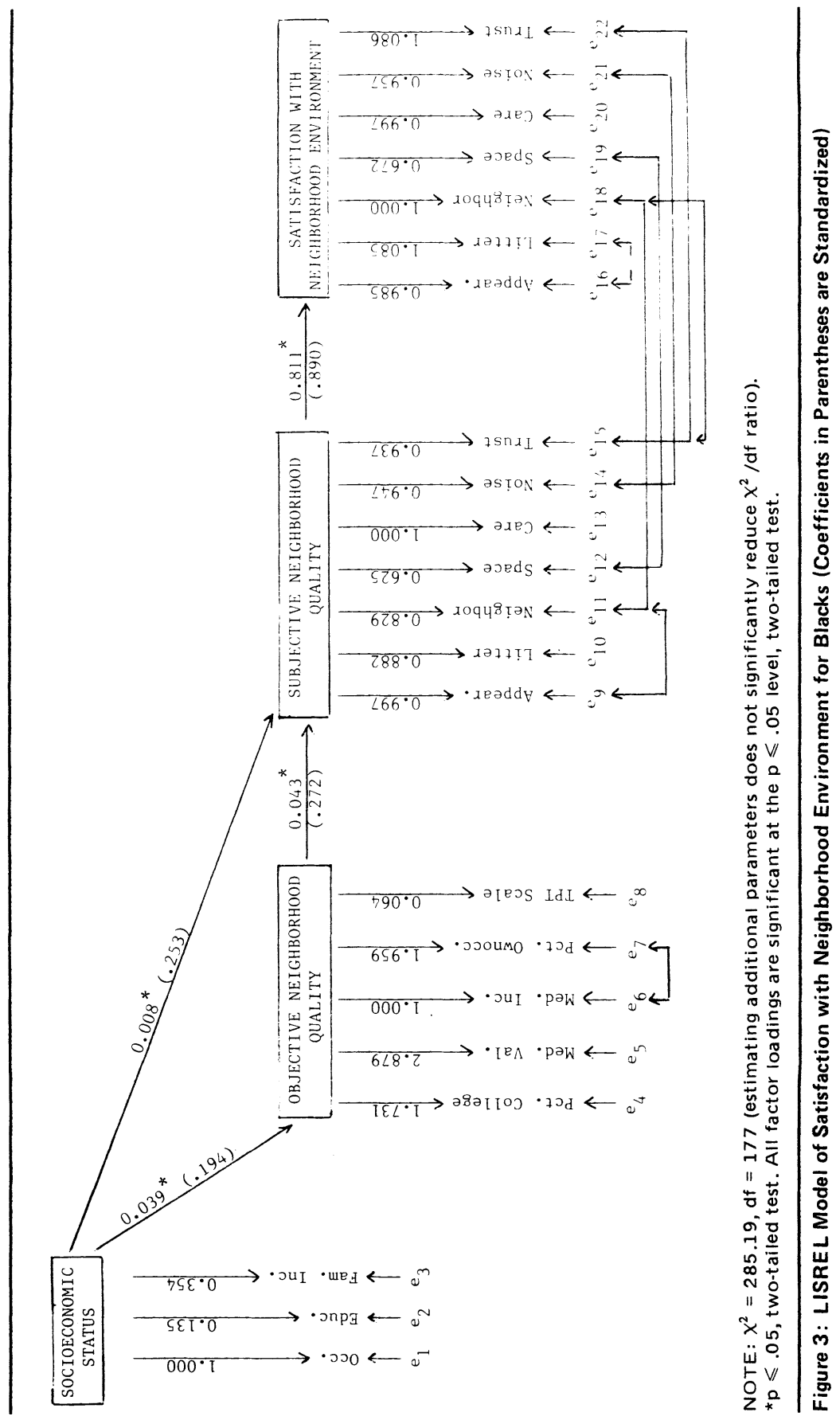


these two coefficients. This test involves two steps. In the first step LISREL estimates the models for blacks and whites as distinct groups simultaneously with the structural parameters leading from objective quality to subjective quality constrained to be equal for both groups. Then the models for blacks and whites are reestimated simultaneously with the parameters leading from objective quality to subjective quality free to take on different values for blacks and whites. A statistically significant conditional chi-square value produced by comparing the fit of the two-groups model in the first step to the fit of the two-groups model in the second step would indicate that the parameter for blacks differs from the parameter for whites.

Estimating the two-groups model with the parameters for the effect of objective quality on subjective quality constrained to be equal produces a chi-square value of 306 with 169 degrees of freedom. Reestimation of the two-groups model, with these parameters free to attain different values for blacks and whites, produces a chi-square value of 293 with 167 degrees of freedom. The conditional chi-square value obtained is 13 with 2 degrees of freedom, significant at the $p<.001$ level. This means there is a statistically significant racial difference in the coefficients leading from objective quality to subjective quality, supporting the hypothesis. ${ }^{12}$

There is also a noticeable racial difference in the effect of socioeconomic status on objective neighborhood quality. For whites (Figure 2) the unstandardized coefficient for this effect is 0.194 . For blacks (Figure 3) this coefficient is much smaller, 0.039. Estimating the models shown in Figure 2 and 3 simultaneously for blacks and whites, with these parameters constrained to be the same for both groups, produces a model chi-square value of 344 with 169 degrees of freedom. Reestimation with these parameters free to differ produces a model chi-square value of 293 with 167 degrees of freedom, giving a conditional chisquare of 51 with 2 degrees of freedom, significant at the $p<.001$ level. Thus this research confirms other findings (Villemez, 1980) that blacks do receive less of a return in the way of objective neighborhood quality for their socioeconomic resources than whites.

\section{SUBJECTIVE VERSUS OBJECTIVE INDICATORS}

The subjective social indicators approach to studying neighborhood or community satisfaction is based on the premise that the standards 
people utilize to evaluate the quality of their residential environments vary according to expectations which are derived largely from experience. However, to date, no systematic attempt has been made to verify this premise. Blacks in the United States have experienced housing market conditions that are strikingly different from those experienced by the majority white population. On the basis of this difference in experiences, the argument has been presented that blacks are likely to have, on average, developed expectations for the environmental quality of their neighborhoods that are different from those of whites. Because blacks of all social classes have fewer housing options available to them as compared to whites, black expectations for the environmental quality of their neighborhoods are consistent with their limited options. The existence of dual standards for evaluating neighborhood environmental quality could account for previous findings that have shown small racial differences in neighborhood satisfaction in spite of noticeable differences in objective neighborhood environmental quality.

The analysis has supported the hypothesis that blacks and whites have different standards for evaluating the environmental quality of their neighborhoods. When controlling for socioeconomic status and a measure of objective environmental quality, blacks report higher environmental quality for their neighborhoods than whites. Further, this difference was found to be produced by blacks turning objective environmental quality into subjective environmental quality at a higher rate than whites.

In this research the focus has been exclusively on how blacks and whites evaluate the environmental (social and physical) quality of their neighborhoods. It is plausible that there are racial differences in the standards by which other dimensions of neighborhood characteristics are evaluated. For example, the sense of safety and security that neighborhoods provide their residents might be evaluated differently by blacks and whites. Since crime rates in black neighborhoods historically have been higher than in white neighborhoods (Skogan and Maxfield, 1981), it is possible that blacks have come to accept as normal a higher risk of victimization than whites. This could result in blacks evaluating the safety and security quality of their neighborhoods higher than whites given similar risks of victimization.

Although little research has examined racial differences in the relationship between victimization and evaluation responses to crime (for example, fear of crime), one study does support this hypothesis. Stafford and Galle (1984) present National Crime Survey data for Chicago showing that for each age and sex category of respondents, 
blacks had much higher victimization rates than whites but either lower or only slightly higher levels of being afraid to go out in their neighborhoods after dark or alone. A multivariate analysis showed race not to have a significant effect on fear of crime once an adjusted victimization rate was controlled. However, because this analysis did not control for socioeconomic status, and since SES is negatively related to victimization and blacks have lower average SES than whites, it is likely that these results mask a tendency for blacks to express lower levels of fear than whites when controlling for SES. These results would be consistent with the hypothesis that, controlling for SES, blacks tend to live in higher-crime areas than whites but express less negative evaluations of them per given level of crime.

Also, it is possible that there are systematic group differences in evaluation standards other than racial ones. For example, members of the lower class, whites as well as blacks, have limited housing opportunities for economic reasons and might develop expectations and evaluation standards according to neighborhood characteristics that they have experienced and for which they have realistic expectations.

That evidence has been produced of a systematic group difference in neighborhood evaluation standards has important implications for future quality-of-life research. It means that assessments of neighborhood quality based on objective indicators might bear little resemblance to the level of quality perceived by neighborhood residents, a critique of the use of objective indicators long noted by subjective quality-of-life researchers.

Further, this evidence has important implications for research following the subjective quality-of-life approach. Nearly all existing studies on this topic have proceeded by asking respondents how satisfied they were with particular dimensions of their neighborhoods and then relating levels of satisfaction with these dimensions to a measure of overall neighborhood satisfaction, identifying the most important components of it. However, the findings imply that by failing to address the processes from which the standards for making evaluations arise, this research might actually be missing the most important components of neighborhood satisfaction ratings.

Accordingly, if one seeks to discover why there is a difference or similarity in the level of neighborhood satisfaction among two or more groups, it is not enough only to determine on which neighborhood dimensions satisfaction levels vary or are the same and how they are related to overall satisfaction. Rather, it is necessary to know something 
of the standards used for evaluating these dimensions and how these standards have developed. Thus this research points out that a full understanding of neighborhood satisfaction must include an analysis of the standards on which neighborhood evaluations are based.

Finally, this research points out an important consideration if equity, or a closer approximation of it, in residential quality is a social policy goal. If two or more groups of people report being equally satisfied with the conditions of their residential environments, does this represent an equitable situation? The research indicates that equity in final outcome, satisfaction, does not necessarily mean there is equity in conditions. The discrepancy between evaluations and actual conditions points out the fallacy of using subjective evaluations, at least of neighborhood quality, as social indicators to inform this type of policy. An undesirable situation might exist if there were, hypothetically, no significant group differences in satisfaction with the residential environment but because of variations in standards for evaluating this environment some groups were, in fact, far less well-off than others.

\section{NOTES}

1. Some research has shown that there are group differences in the neighborhood characteristics that are the most important predictors of overall neighborhood satisfaction (Lee, 1981; Herting and Guest, 1985). However, in these studies no attempt is made to demonstrate that there are group differences in the standards used to evaluate these neighborhood characteristics.

2. Lee (1981) showed that blacks are more likely than whites to report that crime is a problem in their neighborhoods, an indication that blacks are less satisfied with the safety characteristics of their neighborhoods than whites. However, social class and other important compositional variables were not controlled for in this relationship. St. John and Clark (1984b) did not find a racial difference in satisfaction with these characteristics while controlling for social class.

3. The Polk Directory lists the head of each household and a spouse if there is one. After randomly choosing residences, a coin was flipped to choose between the household head and the spouse when appropriate. This procedure is designed to produce a sample that is representative in regard to gender. Potential respondents refusing to participate in the survey either were replaced by resampling from the Polk Directory, or were replaced by substitutes of the same gender living within a three-block radius of the original respondent's residence. This procedure produced a sample whose demographic characteristics closely matched those expected from census data for Oklahoma City.

4. The supplemental black sample was chosen by first identifying census tracts in which $35 \%$ or more of the population was black in 1980 . Approximately $75 \%$ of Oklahoma City's black population lives in these tracts. Having identified these tracts, names were 
drawn at random from the Polk Directory in the manner described in note 3, with those living in the identified tracts retained as potential respondents. Refusals and whites were replaced by black respondents living within a three-block radius of the original respondent's residence.

5. Because this oversampling procedure excludes blacks who live in areas of smaller black concentrations, it was possible that the supplemental sample was biased in regard to socioeconomic status, probably downward, and was not representative of Oklahoma City's black population. However, a comparison of the socioeconomic status and demographic characteristics of the supplemental black sample and the regular black sample did not reveal any statistically significant differences. Thus it is unlikely that combining the black respondents in the supplemental and regular samples systematically biases any of the findings reported for race as an independent variable.

6. The five personal and property safety items included in this factor analysis were perceptions of (1) the need to lock doors when leaving homes for a short period of time, (2) worrying about having homes broken into, (3) the need to keep doors locked while at home, (4) fear of being attacked while walking outside at night, and (5) being able to leave personal property outside and unattended without it being damaged or stolen. The loadings for the seven environmental items on the environmental factor are as follows:

\section{Item}

$\begin{array}{ll}\text { Pride in appearances } & 0.8273 \\ \text { Litter } & 0.6802 \\ \text { Property of others } & 0.6583 \\ \text { Space between houses } & 0.4456 \\ \text { Care of property } & 0.7771 \\ \text { Noise } & 0.7388 \\ \text { Trust of neighbors } & 0.7203\end{array}$

7. The TPT consists of pictorial scales on which 10 housing dimensions can be rated. Each scale is based on a series of photographs that cover the full range of possible housing conditions for each dimension. Ratings of each dimension are made by matching the housing unit being observed to the most similar scale picture. Since ratings are always based on the pictorial scales, the housing surveyor has an unchanging standard of comparison on which to make ratings, giving a more objective quantifiable evaluation of housing conditions. The ratings of the 10 dimensions of housing units are then summed into a composite scale.

8. The loadings obtained from this factor analysis are as follows:

\section{Item}

Percentage college education

Median household income

Median value of housing

Percentage owner-occupied housing

Housing quality (TPT scale)

\section{Loading}

0.8398

0.9564

0.9118

0.6185

0.7087

9. LISREL begins with a variance-covariance matrix (along with means and standard deviations) for all variables included in the analysis. It compares this observed 
matrix with one produced by hypothesized measurement and structural equation models. The measurement model specifies how observable indicators load on unobserved latent constructs or on variables for which there are only single indicators and if there is correlated measurement error among the observable indicators. The structural equation model specifies the relationships that exist among the latent constructs and single indicator variables. In comparing the observed and hypothesized variance-covariance matrices, LISREL produces a chi-square statistic that measures the fit of the hypothesized models to the data. LISREL also produces a statistic that indicates where a poor fit exists between the observed and hypothesized matrices and which measurement or structural equation parameters must be respecified in order to produce a better fit. As a result of this model-fitting procedure, both measurement and structural equation parameters are obtained that closely reproduce the empirically observed relationships among all variables in the analysis. LISREL provides an improvement over more conventional forms of analysis by explicitly modeling the existence of correlated measurement errors among observable indicators of latent constructs rather than assuming, tenuousy, that such correlations do not exist. Further, LISREL's model-fitting procedure allows the data to guide the inclusion or exclusion of relevant parameters, producing models, and parameter estimates for them, that more accurately represent the data.

10. The loadings shown in Figure 1 and subsequent figures are unstandardized loadings in which the metrics are determined by the metric of the loading set equal to 1.0. Thus it is not appropriate to compare the relative magnitudes of these loadings since each is a function of the metric of the relevant variable. See notes 6 and 7 for the loadings for objective and subjective environmental quality in Figure 1 obtained through factor analysis.

11. As a first step in this section of the analysis, it is necessary to show that the loadings for objective and subjective neighborhood quality (that is, the lambda matrices for these two variables) are similar for blacks and whites. It is possible to do this by obtaining the chi-square value for the two-groups model in which the loadings for whites are constrained to equal the loadings for blacks and comparing it with the chi-square value for the two-groups model in which the loadings for whites are free to be different from those for blacks. The conditional chi-square tests produced by these comparisons indicated that there are no statistically significant differences between the relevant loadings for blacks and whites.

12. An alternative explanation for the racial difference in this relationship is that blacks and whites have identical standards for evaluating neighborhood quality but that at any given level of objective quality, black neighborhoods are truly better off. Because no reason this would or could be the case was apparent, the interpretation is as presented.

\section{REFERENCES}

ANDREWS, F. and S. WITHEY (1976) Social Indicators of Well-Being: Americans' Perceptions of Life Quality. New York: Plenum Press.

BERRY, B.J.L. and J. D. KASARDA (1977) Contemporary Urban Ecology. New York: Macmillan.

CAMPBELL, A. (1981) The Sense of Well-Being in America. New York: McGraw-Hill. 
CAMPBELL, A., P. E. CONVERSE, and W. RODGERS (1976) The Quality of American Life. New York: Russell Sage.

DENOWITZ, R. (1980) “Racial succession in New York City, 1960-1970.” Social Forces 59: $440-455$.

FARLEY, R. (1977) "Residential segregation in urbanized areas of the United States: an analysis of social class and racial differences." Demography 14: 497-518.

FREY, W. H. (1979) "Central city white flight: racial and non-racial causes." Amer. Soc. Rev. 44: 425-448.

FRIED, M. and P. GLEICHER (1961) "Some sources of residential satisfaction in an urban slum." J. of the Amer. Institute of Planners 27: 305-315.

GANS, H. (1962) The Urban Villagers. New York: Free Press.

GUEST, A. M. and B. A. LEE (1983a) "Sentiment and evaluation as ecological variables." Soc. Perspectives 26: 159-184.

GUEST, A. M. and B. A. LEE (1983b) "The social organization of local areas." Urban Affairs Q. 19: 217-240.

GULICK, J., C. BOWERMAN, and K. BACK (1962) "Newcomer enculturation in the city: attitudes and participation," pp. 315-358 in F. S. Chapin, Jr., and S. Weiss (eds.) Urban Growth Dynamics. New York: John Wiley.

HERTING, J. R. and A. M. GUEST (1985) “Components of satisfaction with local areas in the metropolis." Soc. Q. 26: 99-116.

HINDELANG, M., M. GOTTFREDSON, and J. GAROFALO (1978) Victims of Personal Crime: An Empirical Foundation for a Theory of Personal Victimization. Cambridge, MA: Ballinger.

JORESKOG, K. G. and D. SORBOM (1981) LISREL V: Analysis of Linear Structural Relationships by Maximum Likelihood and Least Squares Methods. Chicago: National Educational Resources.

KARMEN, A. (1984) Crime Victims: An Introduction to Victimology. Monterey, CA: Brooks/Cole.

LADEWIG, H. and G. C. McCANN (1980) "Community satisfaction: theory and measurement." Rural Sociology 45: 110-131.

LAND, K. C. (1971) “On the definition of social indicators." Amer. Sociologist 6: 322-325.

LANSING, J. B. and R. W. MARANS (1969) “Evaluations of neighborhood quality.”J. of the Amer. Institute of Planners 75: 195-199.

LEE, B. A. (1981) "The urban unease revisited: perceptions of local safety and neighborhood satisfaction among metropolitan residents." Social Sci. Q. 62: 611-629.

MARANS, R. W. and W. RODGERS (1975) "Toward an understanding of community satisfaction," pp. 229-352 in A. Hawley and V. Rock (eds.) Metropolitan America in Contemporary Perspective. New York: Halsted.

MARSHALL, H. (1979) "White movement to the suburbs." Amer. Soc. Rev. 44:975-994.

MILLER, F., S. TSEMBERIS, G. P. MALIA, and D. GREGA (1980) "Neighborhood satisfaction among urban dwellers." J. of Social Issues 36 (Summer): 101-117.

MULlER, P. J. (1981) Contemporary Suburban America. Englewood Cliffs, NJ: Prentice-Hall.

NEWMAN, S. J. and G. J. DUNCAN (1979) "Residential problems, dissatisfaction and mobility." J. of the Amer. Planning Assn. 45: 154-166. 
RODGERS, W. L. (1982) "Density, crowding, and satisfaction with the residential environment." Social Indicators Research 10: 75-102.

SKOGAN, W. and M. MAXFIELD (1981) Coping with Crime: Individual and Neighborhood Reactions. Beverly Hills, CA: Sage.

STAFFORD, M. and O. GALLE (1984) "Victimization rates, exposure to risk, and fear of crime." Criminology 22: 173-185.

STIPAK, B. and C. HENSLER (1983) "Effect of neighborhood racial and socioeconomic composition on urban residents' evaluation of their neighborhoods." Social Indicators Research 12: 311-320.

ST. JOHN, C. and F. CLARK (1984a) "Race and social class differences in the characteristics desired in residential neighborhoods." Social Sci. Q. 65: 803-813.

ST. JOHN, C. and F. CLARK (1984b) "Racial differences in dimensions of neighborhood satisfaction." Social Indicators Research 15: 43-60.

SUTTLES, G. (1968) The Social Order of the Slum. Chicago: Univ. of Chicago Press.

SUTTLES, G. (1972) The Social Construction of Communities. Chicago: Univ. of Chicago Press.

TAEUBER, K. and A. TAEUBER (1965) Negroes in Cities. Chicago: Univ. of Chicago Press.

Texas Department of Community Affairs (1973) Housing Data Collection. Austin, T: Author.

VILLEMEZ, W. (1980) "Race, class, and neighborhood: differences in the residential return on individual resources." Social Forces 59: 414-430.

WILSON, R. L. (1962) "Liveability of the city: attitudes and urban development," pp. 359-399 in F. S. Chapin, Jr., and S. Weiss (eds.) Urban Growth Dynamics. New York: John Wiley.

Craig St. John is Associate Professor of Sociology at the University of Oklahoma. His research interests focus on community formation, change, and evaluation. His articles on these topics have appeared recently in Social Science Quarterly, Social Indicators Research, and Sociological Spectrum. 